\title{
Una historia de la humanidad contada desde la comunicación social
} A history of mankind told from the social communication

\author{
Luis Mauro Sujatovich luissujatovich@hotmail.com \\ http://orcid.org/0000-0003-1537-2942 \\ Universidad Nacional de Quilmes (Argentina)
}

\section{Resumen}

El artículo ofrece una reseña del libro Historia mundial de la comunicación escrito por José María Perceval, doctor en Ciencias Sociales y profesor del Departamento de Periodismo y de Ciencias de la Comunicación de la Universitat Autónoma de Barcelona (España). El texto propone un recorrido desde los albores de la humanidad hasta la actualidad, desde una perspectiva original, ya que cada modificación o cambio de hábito cultural está sometido a la interpretación comunicacional. De tal forma que acaba conformando una interesante versión de la evolución humana tanto cultural como tecnológica.

Palabras clave: historia universal; comunicación social ; reseña; libro. 


\section{Abstract}

The article provides an overview of the book world history of communication written by the PhD in Social Sciences and professor of the Department of Journalism and Communication Sciences of the Universitat Autónoma de Barcelona (Spain). The text proposes a tour since the dawn of mankind until the present day, but from an original perspective, since each modification or change cultural habit is subject to communicational interpretation. In such a way that it ends up forming an original and interesting version of human evolution both cultural and technological.

Keywords: universal history; social communication; review; book.

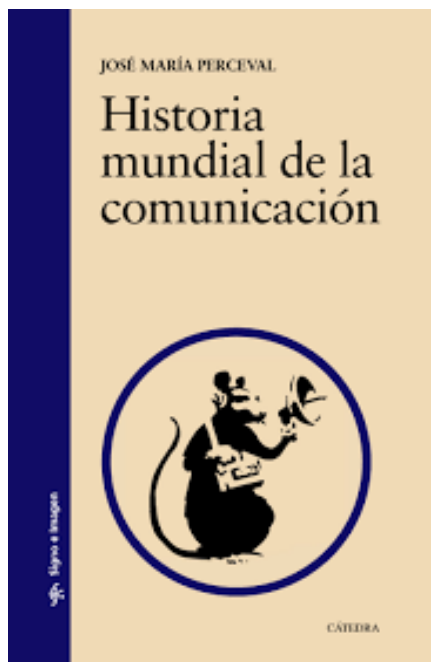

Los debates acerca de la condición epistemológica de la comunicación social aún no han cesado. Ni siquiera la irrupción de los fervorosos publicistas de la tecnología digital ha podido dirimirlo: ¿es una disciplina o es apenas un lábil acervo de estudios sin método propio?

Las predicciones de un inexorable destino audiovisual traen consigo la confortable certeza del saber unificado y sólido para (jal fin!) ascender a la comunicación social al podio de las ciencias sociales consagradas, aunque el costo sea privarse de aquellas preguntas e indagaciones que permiten ampliar sus fronteras y establecer diálogos productivos con las demás ciencias sociales. Basta revisar las tesis, publicaciones y artículos de los últimos lustros para advertir que la decisión de la mayoría de los protagonistas va en un mismo sentido: resignar preguntas y métodos interdisciplinarios a cambio de una virtual certidumbre que permita reproducir carreras, subsidios y distinciones de consagrada impronta digital.

Sin embargo algunos investigadores, como José María Perceval, insisten en brindarle a la comunicación una densidad conceptual que lejos de ofrecer respuestas tranquilizadoras, opta por incomodar con hipótesis creativas y abiertas que tanto generan asombro como incitan a continuar indagando. Es decir, se dan a la tarea de hacer y difundir la ciencia sin que ello signifique sacrificar su complejidad. Un notable ejemplo de esta actitud constructiva en relación a la ciencia, lo ofrece la investigación titulada Historia mundial de la comunicación. Sus arriesgadas conjeturas acerca de las profundas relaciones entre el desarrollo del ser humano y 
sus posibilidades de comunicación, representan un aporte insoslayable tanto para los estudiantes como para los docentes y profesionales de la comunicación social. Su afán exploratorio lo impulsa a agotar las huellas de los primeros grupos humanos para indagar en sus mutaciones a lo largo del tiempo y así conformar un relato explicativo acerca de cómo diversas partes del cuerpo, por ejemplo la vista, se fue modificando para satisfacer las necesidades de supervivencia. En la primera etapa, denominada oral gestual, sostiene un argumento tan sólido como poco explorado en las carreras de grado: durante siglos la comunicación fue una competencia fisiológica relacionada con la adaptación al medio. El primer impulso de su desarrollo no fue cultural, sino más bien biológico.

La crónica comunicacional de la historia de la humanidad continúa con la etapa gráfica. El sinuoso sendero de las múltiples escrituras de la antigüedad hasta la invención de la imprenta, le brindan la ocasión al autor para abordar temas tan disímiles como el invento de la moral, del Estado y de la retórica; la ruta de la seda, el cero y la pólvora, sin abandonar la impronta elegida.

El advenimiento de las grandes sociedades industriales (presentada en tres etapas) también suscitó que las formas de comunicar sufrieran transformaciones sustanciales. Pero no se aborda este vertiginoso período como una sucesión escolarizada de tecnologías que se vuelven obsoletas ante la irrupción de una más sofisticada y completa. Por el contrario, se buscan las raíces del proceso en los cambios políticos y religiosos en Francia, en Inglaterra y luego en Estados Unidos, para articular la expansión del capitalismo junto a la electricidad, la consolidación de los Estados nación con la aparición de la profesión del periodista, del empresario mediático y de los grandes públicos consumidores de información y de entretenimiento.

La reflexión incluida en el prefacio:

Cada vez que la humanidad ha encontrado un nuevo soporte de comunicación, este se le ha presentado con todos los atractivos de unas maravillosas zapatillas rojas. Y la humanidad ha conseguido mucho más de lo que esperaba. Para lo bueno y para lo malo (Perceval, 2015: 6).

se vuelve aún más necesaria para recorrer la segunda mitad del siglo $X X$ sin tropezarse ante tantas pantallas y tanto vértigo. El afán de las sociedades contemporáneas por la velocidad, la conexión y la imagen como elemento central en la constitución de los valores, sentidos y expresiones válidas (y deseadas) provocan en el autor la precaución necesaria para no volverse un integrado que celebra a los nativos digitales sin mayor argumento que los patrocinantes de sus investigaciones. 
Las preguntas postuladas en la última etapa llamada digital, sobre las redes sociales y su relación con la política y la democracia, permiten no sólo una aproximación equilibrada entre el auge y la cautela, sino también comprender que los dispositivos digitales sólo potencian las ambiciones comunicativas de la humanidad, no las fundan.

Uno de los grandes desafíos que el análisis de la comunicación social afronta se dirime en una dicotomía de enormes consecuencias: ¿cómo debe actuar la sociedad frente a las zapatillas rojas? Si es en términos prácticos, bastará con comprar un celular sofisticado e inscribirse en cualquier curso virtual sobre comunicación digital. En cambio, si se pretende articular su devenir con los aportes de las otras Ciencias Sociales y establecer una continuidad que otorgue densidad conceptual y remita a preguntas que deben revisarse con criticidad y metodologías pertinentes, la lectura del libro es un buen comienzo.

No se trata de rechazar las zapatillas rojas, sólo se invita a conocer su historia.

\section{Bibliografía}

Perceval, J. M. (2015). Historia mundial de la comunicación. Barcelona: Ediciones Cátedra. 